\title{
PENGARUH KOMPENSASI FINANSIAL LANGSUNG TERHADAP TURNOVER INTENTION DENGAN KEPUASAN KERJA SEBAGAI VARIABEL INTERVENING (Pada Ratu Swalayan Dampit Kabupaten Malang)
}

\author{
Denny Irawati Agustin \\ Department of Management FEB UMM \\ E-mail: denny.irawatiagustin@gmail.com
}

\begin{abstract}
This study aim describing direct financial compensation and turnover intention in Ratu Supermarket, Dampit, Malang Regency, determining influence of direct financial compensation on employees' turnover intention, and identifying job satisfaction that mediates the influence of direct financial compensation on the turnover intention in Ratu Supermarket, Dampit,Malang Regency.The population was all employees amounted to 32 people. The sampling technique used was population sample, in which all population was used as the sample.Data collection techniques used interviews, questionnaires and documentation. The data were analyzed by using Path Analysis and Sobel Test. The result of the study showed that direct financial compensation had a good criteria whereas job satisfaction had a high criteria, and turnover intention have a high criteria. From the Path Anlysis and Sobel Test, it indicates that direct financial compensation had a significant influence on turnover intention, and the other Path Anlysis showed that direct financial compensation and job satisfaction had significant influence on turnover intention. The result of the analysis confirmed that job satisfaction could mediate direct financial compensation that influence the turnover intention in Ratu Supermarket, Malang Regency.
\end{abstract}

Keywords: direct financial compensation, job satisfaction, turnover intention

\section{PENDAHULUAN}

Turnover intention telah menjadi masalah serius bagi banyak perusahaan. Dampak negatif yang dirasakan akibat terjadinya turnover intiention adalah banyaknya karyawan yang keluar dari perusahaan, sehingga butuh waktu serta biaya baru dalam merekrut karyawan baru.

Fenomena terjadinya turnover intention dialami oleh Ratu Swalayan yang beralamatkan di Jl. Semeru Selatan Dampit, Kabupaten
Malang. Berdasarkan hasil wawancara yang dilakukan dengan owner Ratu Swalayan menyatakan perusahaannya sedang mengalami indikasi turnover intention. Keadaan ini ditujukan oleh perilaku karyawan yang tidak masuk kerja/absen. Dalam satu bulan kerja, selalu ditemukan karyawan absen atau membolos dan meminta ijin bekerja. Tingkat absensi tersebut merupakan salah satu indikasi terjadinya turnover intention, dan akan merugikan perusahaan. 


\begin{abstract}
Karyawan juga melakukan pelanggaran perturan kerja dan pelanggaran lainnya karena karyawan merasa kurang puas terhadap gaji yang diberikan oleh perusahaan. Perusahaan memberi gaji dibawah peraturan upah minimum kabupaten Malang yaitu sebesar Rp. 2.188.000.

Kurang puas terhadap rekan
\end{abstract} kerja juga ditunjukkan dengan kecilnya rasa sosial yang ditunjukkan karyawan, yaitu adanya sikap kurang mau saling membantu saat bekerja contohnya, sebagian karyawan melakukan pekerjaannya sesuai dengan jam kerja yang ditentukan, dan sebagian lainnya bersantai karena merasa sedang tidak ada konsumen yang harus dilayani.

Menanggapi hal ini owner Ratu Swalayan mengambil tindakan agar indikator turnover intention yang sedang dialami perusahaannya tidak berlanjut terus menerus. Owner memenuhi kebutuhan karyawan secara tidak langsung dengan cara memberikan insentif ketika karyawannya memiliki kinerja yang baik, selain itu owner juga memberikan bonus berupa vocher belanja sembako sebesar Rp.150.000 ketika perusahaan memiliki keuntungan yang besar. Hal tersebut bertujuan agar karyawannya dapat merasa lebih puas dan untuk menambah semangat kerja karyawannya.

Berdasar fenomena yang telah dijabarkan, penelitian ini akan menguji seberapa besar pengaruh kompensasi finansial langsung dan kepuasan kerja terhadap turnover intention. Rumusan masalah yang akan diteliti dalam penelitian ini adalah sebagai berikut :
Bagaimana kompensasi finansial langsung, turnover intention, dan kepuasan kerja karyawan? (2) Apakah kompensasi finansial langsung berpengaruh signifikan terhadap turnover intention?, (3) Apakah kompensasi finansial langsung berpengaruh signifikan terhadap turnover intention dengan kepuasan kerja sebagai variabel intervening?

\section{TINJAUAN PUSTAKA}

Penelitian terdahulu yang digunakan dalam penelitian ini adalah sebagai berikut : 1) Sulastri Irbayuni, (2012). Alat analisis yang digunakan adalah regresi linier berganda. Hasil dari penelitian tersebut adalah Kompensasi dan kepuasan kerja tidak berpengaruh terhadap keinginan untuk pindah kerja. (2) Adi Bibowo dan Erni Masdupil, (2015). Alat analisis yang digunakan adalah path analysis. Hasil dari penelitiannya yaitu Terdapat pengaruh signifikan dari variabel kepuasan kerja terhadap turnover intention. Kompensasi berpengaruh siginifikan terhadap turnover intention. (3) Rita Andini, (2006). Alat analisis yang digunakan adalah regresi linier berganda. Hasil dari penelitian tersebut yaitu Kepuasan kerja berpengaruh negative secara keseluruhan terhadap turnover.

(4) Emeraldo Rizki, (2015). Alat analisis yang digunakan adalah path analysis yang memiliki hasil Kompensasi berpengaruh negatif signifikan terhadap turnover intention, kepuasan kerja tidak berpengaruh terhadap turnover intention, kompensasi memiliki pengaruh positif signifikan terhadap 
kepuasan kerja. Hasil dari analisis jalur menunjukkan bahwa variabel kepuasan kerja tidak dapat memediasi hubungan pengaruh antara variabel kompensasi dan turnover intention.

Turnover intention adalah rasa ingin keluar dari tempatnya bekerja yang dirasakan oleh karyawan. Mobley, Horner dan Hollingsworth, 1978 dalam Grant et al., (2001) menyatakan bahwa keinginan untuk pindah dapat dijadikan gejala awal terjadinya turnover dalam sebuah perusahaan. Menurut March dan Simon (dalam Mobley, 1986) ada beberapa faktor yang menjadi latar belakang terjadinya turnover intention antara lain kepuasan kerja, kemungkinan transfer, serta tersedianya alternatif pekerjaan yang lain.

Menurut Harnoto (2002) ada beberapa indikator yang menunjukkan terjadinya turnover intention pada karyawan antara lain: (1) Absensi yang meningkat, (2) Karyawan yang mulai malas bekerja, (3) Peningkatan pelanggaran tata tertib, (4) Peningkatan protes terhadap atasan, (5) Perilaku positif yang berlebihan.

Menurut Locke (dalam Luthans, 2005) kepuasan kerja merupakan keadaan emosional yang positif dari karyawan yang ditimbulkan dari penghargaan atas suatu pekerjaan yang telah mereka lakukan. Kepuasan kerja ini bersifat individual, tingkat kepuasan antara individu yang satu dengan yang lain berbeda-beda. Biasanya setiap individu akan merasa puas atas pekerjaannya apabila pekerjaan yang dilakukan telah sesuai dengan harapan dan tujuan ia bekerja.

Menurut Wibowo (2007) yang mengutip dari pendapat Kreitner dan Kinicki menyatakan ada lima faktor yang dapat mempengaruhi timbulnya kepuasan kerja diantaranya, pemenuhan kebutuhan, perbedaan, pencapaian nilai, keadilan, serta dispositional atau komponen genetik.

Ada lima indikator kepuasan kerja yang di jelaskan oleh Luthans (2006) antara lain : (1) Kepuasan terhadap gaji, (2) Kepuasan terhadap pekerjaan itu sendiri, (3) Kepuasan terhadap kesempatan promosi, (4) Kepuasan terhadap supervisi/ pengawasan , (5) Kepuasan terhadap rekan kerja.

Mathis dan Jackson (2004) membagi jenis-jenis kompensasi menjadi dua yaitu kompensasi langsung/direct compensation dan kompensasi tidak langsung/indirect compensation.

Kompensasi langsung terdiri dari gaji pokok atau upah dan gaji variabel seperti bonus, insentif, dan program kepemilikan saham oleh karyawan. Sedangkan kompensasi tidak langsung berbentuk tunjangantunjangan seperti program pensiun, program rekreasi, tunjangan keluarga, asuransi kesehatan, keamanan kerja, cuti kerja dan sebagainya.

Kompensasi finansial langsung adalah pembayaran berbentuk uang yang karyawan terima secara langsung dalam bentuk gaji/upah, tunjangan ekonomi, bonus dan komisi. Gaji adalah balas jasa yang dibayar secara periodik kepada karyawan tetap serta mempunyai jaminan yang pasti, sedangkan upah adalah balas jasa yang dibayarkan 
kepada pekerja dengan berpedoman pada perjanjian yang disepakati pembayarannya.

Indikator kompensasi finansial langsung menurut Mondy dan Noe
(2003) adalah sebagai berikut: (1) Gaji, (2) Upah, (3) Insentif. Dari uraian diatas dapat digambarkan dalam kerangka pikir yang bisa dilihat pada Gambar 1 dibawah ini.

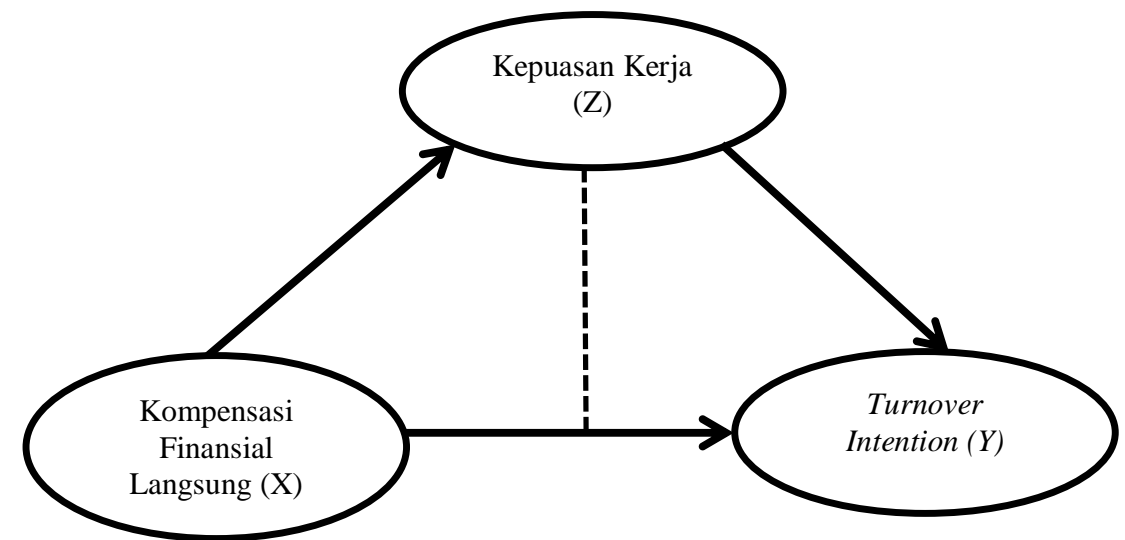

Gambar 1. Hubungan Kompensasi Finansial Langsung, Kepuasan Kerja dan Turnver Intention

Berdasarkan

pemaparan fenomena, rumusan masalah, dan landasan teori yang telah di kemukakan maka dirumuskan hipotesis sebagai berikut: (1) kompensasi finansial langsung berpengaruh signifikan terhadap turnover intention pada Ratu Swalayan Dampit Kabupaten Malang, hipotesis (2) kompensasi finansial langsung berpengaruh signifikan terhadap turnover intention melalui kepuasan kerja sebagai variabel intervening pada Ratu Swalayan Dampit Kabupaten Malang.

\section{METODE PENELITIAN}

Penelitian ini dilakukan di Ratu Swalayan Dampit Kabupaten Malang yang berada di Jalan Semeru Selatan Dampit Kabupaten Malang. Jenis penelitian yang dilakukan berupa penelitian survey. Populasi dalam penelitian ini adalah keseluruhan karyawan Ratu
Swalayan Dampit Kabupaten Malang yang berjumlah 32 karyawan.

Sampel pada penelitian ini yaitu keseluruhan populasi dijadikan sebagai sampel penelitian. Dalam penelitian ini populasi adalah seluruh karyawan yang berjumlah 32 karywan sehingga sampel pada penelitian ini adalah 32 karyawan Ratu Swalayan Dampit Kabupaten Malang.

Jenis data yang digunakan dalam penelitian ini adalah data kuantitatif dan kualitatif sedangkan sumber data adalah data primer dan data sekunder. Teknik pengumpulan data memakai wawancara, kuisioner dan juga dokumentasi. Sedangkan teknik pengukuran variabel menggunakan penilaian skala likert yang kemudian responden akan diberikan lima pilihan jawaban, setiap pilihan adalah sangat setuju (SS), setuju (S), netral (N), tidak setuju (TS), sangat tidak setuju (STS). 


\section{HASIL PENELITIAN DAN PEMBAHASAN}

Hasil statistik dari kompensasi finansial langsung terhadap turnover intention dengan kepuasan kerja sebagai variabel intervening dengan hasil yang telah diolah menggunakan SPSS

Tabel 1. Hasil Analisis Jalur Kompensasi Finansial Langsung terhadap Turnover Intention

\begin{tabular}{lcccc}
\hline \multicolumn{1}{c}{ Variabel } & $\mathrm{B}$ & $\mathrm{T}$ & Sig t & Keterangan \\
\hline $\begin{array}{c}\text { Kompensasi Finansial } \\
\text { Langsung (X) }\end{array}$ & -0.737 & -5.980 & 0.00 & Signifikan \\
\hline $\begin{array}{l}\text { t Tabel }=2.042 \\
\text { R Square }=0.544\end{array}$ & & & & \\
\hline
\end{tabular}

\begin{abstract}
Dari Tabel 1. Dapat dijelaskan bahwa pengaruh kompensasi
\end{abstract} finansial langsung (X) terhadap turnover intention $(\mathrm{Y})$ memiliki nilai pengaruh sebesar $-0,737$ artinya apabila kompensasi finansial langsung yang terdiri dari ketepatan waktu penerimaan gaji, kesesuaian gaji yang diterima dengan UMK, kesesuaian gaji dengan kontrak kerja, kepuasan bonus yang diterima dengan kesepakatan kontrak kerja, meningkat 1 satuan maka turnover intention menurun sebesar 0,737 Hasil tersebut menujukkan apabila kompensasi finansial langsung meningkat lebih tinggi maka turnover intention yang meliputi tingkat absensi,tingkat kemalasan dalam bekerja, tingkat pelanggaran terhadap tata tertib, tingkat protes kepada atasan dan tingkat perilaku positif yang berlebihan dalam bekerja akan lebih rendah.

Koefisien determinasi $\left(\mathrm{R}^{2}\right)$ yang digunakan untuk mengetahui besarnya kontribusi variabel kompensasi finansial langsung (X) trerhadap variabel turnover intention (Y) diperoleh hasil sebesar 0,544. Hasil tersebut menujukkan bahwa turnover intention yang dipengaruhi oleh kompensasi finansial langsung sebesar $54,4 \%$ dan sisanya sebesar $45,6 \%$ dipengaruhi oleh variabel lain.

Hasil yang diperoleh dari pengujian hipotesis pertama menggunakan uji t adalah bahwa variabel kompensasi finansial langsung berpengaruh signifikan terhadap turnover intention dan memperoleh hasil nilai $-t_{\text {hitung }}$ sebesar -5.980 dengan signifikansi sebesar 0.00 dan $-t_{\text {tabel }}$ sebesar 2.045. Dari hasil tersebut menujukkan bahwa variabel kompensasi finansial langsung (X) berpengaruh signifikan terhadap turnover intention (Y), karena memperoleh hasil $-t_{\text {hitung }}$ lebih kecil daripada $t_{\text {tabel }}(-5.980<-2.045)$ maka dapat disimpulkan $H_{O}$ ditolak dan $H_{a}$ diterima yang berarti variabel kompensasi finansial langsung berpengaruh negatif signifikan terhadap turnover intention. Hal ini merujuk pada penelitian Emeraldo (2015) serta Bibowo dan Masdupil (2015).

Selanjutnya hasil dari pengujian hipotesis kedua menggunakan uji $\mathrm{F}$ dapat dikatakan bahwa kompensasi finansial langsung (X), dan kepuasan kerja (Z), berpengaruh signifikan terhadap turnover intention (Y). 
Untuk mengetahui apakah variabel independent mempunyai pengaruh secara signifikan terhadap variabel dependent atau tidak berpengaruh maka digunakan uji $\mathrm{F}$ (F-test). Pengujian hipotesis kedua menggunakan uji $\mathrm{F}$ atau uji simultan dilakukan dengan membandingkan antara $\mathrm{F}_{\text {hitung }}$ dengan $\mathrm{F}_{\text {tabel }}$.

Berdasarkan hasil analisis maka hasil uji $\mathrm{F}$ dapat disajikan pada Tabel 2. di bawah ini:

Tabel 2. Hasil Uji F

\begin{tabular}{cccc}
\hline Nilai $\mathrm{F}_{\text {hitung }}$ & Nilai $\mathrm{F}_{\text {tabel }}$ & Sig. & Keterangan \\
\hline 27.451 & 3,33 & 0,000 & $H_{a}$ Diterima \\
\hline
\end{tabular}

Dari hasil uji $\mathrm{F}$ pada Tabel 2. didapatkan $\mathrm{F}$ hitung sebesar 27,451 dengan tingkat signifikansi sebesar 0,000. Dari perhitungan $F$ tabel sebesar 3,33, dan dibandingkan maka nilai $\mathrm{F}$ tabel yang nilainya lebih kecil berarti menerima hipotesis yang diajukan dan nilai signifikannya $0,000<0,05$ yang berarti variabel memiliki signifikansi yang baik, sehingga $H_{a}$ diterima dan $H_{O}$ ditolak yang berarti kompensasi finansial langsung dan kepuasan kerja berpengaruh signifikan secara bersama-sama terhadap turnover intention karyawan Ratu Swalayan Dampit Kabupaten Malang.

Berdasarkan hasil dari uji t yang menguji pengaruh antara kompensasi finansial langsung terhadap turnover intention menunjukkan bahwa kompensasi finansial langsung dapat berpengaruh negatif signifikan terhadap turnover intention karyawan di Ratu Swalayan Dampit Kabupaten Malang. Kompensasi finansial langsung secara parsial/individu memiliki pengaruh negatif secara langsung terhadap turnover intention karyawan, hal ini dikarenakan kompensasi finansial langsung memiliki manfaat dan tujuan berbeda dan penting bagi karyawan, sehingga apabila kompensi finansial langsung tidak bisa memenuhi kebutuhan para karyawan maka hal tersebut dapat memunculkan keinginan karyawan untuk keluar dari perusahaan dan mencari pekerjaan lain dengan harapan mendapat kompensasi yang lebih tinggi dari perusahaan lain, dengan kata lain kompensasi finansial langsung bersifat negatif bagi karyawan. Hasil tersebut menjelaskan bahwa, semakin baik kompensasi finansial yang diterima maka semakin rendah niat karyawan untuk keluar dari perusahaan (turnover intention).

Pernyataan tersebut sejalan dengan pendapat Lieke (2008) kompensasi mempunyai pengaruh yang besar dalam penarikan karyawan, motivasi, produktivitas, serta tingkat perputaran karyawan .

Hasil analisis uji t menjelaskan bahwa kompensasi finansial langsung (X), dan kepuasan kerja (Z), berpengaruh signifikan secara parsial terhadap turnover intention (Y). Untuk mengetahui apakah variabel independent mempunyai pengaruh secara signifikan terhadap variabel dependent atau tidak berpengaruh maka digunakan hasil uji $t$ dengan membandingkan $t_{\text {hitung }}$ atau sig $t$ dibandingkan dengan $t_{\text {tabel }}$ 
Tabel 3. Hasil Uji t

\begin{tabular}{cccc}
\hline Variabel & Nilai t $_{\text {hitung }}$ & Nilai t $_{\text {tabel }}$ & Sig. \\
\hline $\begin{array}{c}\text { Kompensasi Finansial } \\
\text { Langsung }\end{array}$ & -2.745 & 2.045 & 0,010 \\
Kepuasan Kerja & -3.046 & 2.045 & 0,005 \\
\hline
\end{tabular}

Pengaruh variabel kompensasi finansial langsung (X) terhadap turnover intention (Y) dari hasil perhitungan parsial menunjukkan bahwa pada taraf nyata 5\% ( $a=$ $0,05)$ diperoleh nilai $t_{\text {tabel }}$ sebesar 2,045. Dengan pengujian statistik diperoleh nilai $t_{\text {hitung }}$ sebesar $-2,745$, karena - $t$ hitung $<-t_{\text {tabel }}$ dan nilai signifikan diatas 0,05 yaitu 0,10 maka dapat disimpulkan bahwa secara parsial variabel kompensasi finansial langsung $(\mathrm{X})$ berpengaruh signifikan terhadap turnover intention (Y). Maka $H_{o}$ Ditolak dan $H_{a}$ Diterima yang berarti variabel kompensasi finansial langsung memiliki pengaruh secara signifikan terhadap variabel turnover intention.

Pengaruh kepuasan kerja (Z) terhadap turnover intention (Y) menunjukkan bahwa, pada taraf nyata $5 \%(a=0,05)$ diperoleh nilai tabel sebesar -2,045. Dengan pengujian statistik diperoleh nilai $-\mathrm{t}$ hitung sebesar -3.046 , karena $-\mathrm{t}_{\text {hitung }}<$ -t tabel dan nilai signifikan sama dengan 0,05 maka dapat disimpulkan bahwa secara parsial variabel kepuasan kerja (Z) berpengaruh secara signifikan terhadap turnover intention (Y). Maka $H_{o}$ Ditolak dan $H_{a}$ diterima yang berarti variabel kepuasan kerja memiliki pengaruh secara signifikan terhadap variabel turnover intention.

Hipotesis 2 yang menyatakan bahwa diduga kompensasi finansial berpengaruh signifikan terhadap Turnover Intention melalui kepuasan kerja dapat dilihat dengan cara menggunakan uji sobel. Variabel kepuasan kerja dapat dinyatakan memediasi pengaruh kompensasi finansial langsung terhadap turnover intention apabila nilai $-t_{\text {hitung }}<-t_{\text {tabel }}$ Hasil dari uji sobel dapat dilihat pada Tabel 4 dibawah ini:

Tabel 4. Hasil Uji Sobel

\begin{tabular}{ccccc}
\hline Variabel & Std. Eror & t Hitung & Signifikansi & Keterangan \\
\hline $\mathrm{X}-\mathrm{Z}-\mathrm{Y}$ & 0.125 & -2.561 & 0.010 & Signifikan \\
\hline
\end{tabular}

Berdasarkan Tabel 4. tersebut dapat diambil kesimpulan bahwa variabel kepuasan kerja dapat memediasi pengaruh dari Variabel kompensasi finansial langsung terhadap variabel turnover intention dilihat dari nilai $t_{\text {hitung }}$ sebesar
-2.561 yang lebih kecil dari $-t_{\text {tabel }}$ yang sebesar -2.045 .

Sobel test menunjukan bahwa, variabel kepuasan kerja dapat memediasi pengaruh kompensasi finansial langsung terhadap turnover intnetion. Hal ini dibuktikan dengan 
hasil uji sobel yang memperoleh nilai $t_{\text {hitung }}$ sebesar -2.561 nilai ini lebih kecil dari 2.045 dan dinyatakan signifikan. Maka kepuasan kerja dapat disebut sebagai mediasi parsial. Hal ini diperkuat dengan hasil pengujian hipotesis secara parsial yang menunjukan variabel kompensasi finansial langsung dan variabel kepuasan kerja berpengaruh terhadap turnover intention secara parsial. Hal ini berarti bahwa apabila kompensasi finansial langsung semakin baik dan kepuasan kerja semakin tinggi, maka turnover intention yang terjadi akan semakin rendah.

Ratu Swalayan Dampit Kabupaten Malang dirasa telah cukup berhasil dalam memenuhi kebutuhan finansial langsung karyawannyatetapi masih ada karyawan yang belum setuju akan baiknya tingkat kompensasi finansial yang diberikan, dan dapat menangani dengan baik kepuasan kerja dari sebagian karyawannya, tetapi ada sebagian lain yang masih belum memiliki kepuasan kerja tersebut. Dengan keadaan yang demikian masih belum dapat mengatasi tingginya tingkat turnover intention di perusahaan tersebut.

\section{SIMPULAN}

Berdasarkan hasil penelitian dan pembahasan maka disimpulkan sebagai berikut: (1) Kompensasi finansial langsung sudah baik, kepuasan kerja yang tinggi dan turnover intention tinggi. (2) Variabel kompensasi finansial langsung berpengaruh signifikan terhadap turnover intention. (3) Variabel kompensasi finansial langsung berpengaruh terhadap variabel turnover intention dengan kepuasan sebagai variabel intervening.

Saran yang diberikan: (1) Owner hendaknya bisa menciptakan rasa loyalitas karyawan terhadap perusahaannya dengan berbagai pendekatan, misalnya dengan memberikan insentif apabila kinerja karyawan baik. (2) Pihak perusahaan seharusnya meningkatkan kepuasan kerja karyawan untuk menjaga loyalitas karyawan kepada perusahaan. meningkatkan kenyaman karyawan terhadap pekerjaannya itu sendiri, meningkatkan tingkat kenaikan jabatan/promosi yang ada di perusahaan, meningkatkan rasa puas karyawan terhadap atasan dengan mendukung pekerjaan karyawan itu sendiri, dan menciptakan lingkungan kerja yang nyaman agar karyawan dapat merasa nyaman untuk bekerja dengan rekan kerjanya.

Pihak perusahaan dapat memberikan insentif untuk karyawan yang memiliki kinerja baik hal tersebut dilakukan untuk menambah kepuasan kerja dan berdampak pada meminimalisir turnover intention yang terjadi diperusahaan.

\section{DAFTAR PUSTAKA}

Grant Kent, David W. Cravens, Geor ge S. Low and William C.Moncr ief. (2001). TheRole of Satisfac tion With Territory Design on the Motivation, Attitudes, and W ork Outcomes of Sales people. Journal of the Academy of Mar keting Science, Volume 29, No. 2, P. 165-178. 
Harnoto. (2002). Manajemen Sumber Daya Manusia. Edisi ke-2. PT. Prehallindo: Jakarta.

Irbayuni, Sulastri. (2012). Pengaruh Kompensasi, Kepuasan Kerja, dan Komitmen Organisasi terhadap keinginan untuk berpindah kerja (Pada PT. Surya Sumber Daya Energi Surabaya). UPN Veteran, Jurnal Neo-Bis, Vol 6 No.1, Juni 2012.

Lieke. 2008. Jurnal Pengaruh Kompensasi dan Motivasi Kerja Terhadap Komitmen Organisasi. Luthans, Fred. (2005). Perilaku Organisasi. Edisi Sepuluh, Diterjemahkan oleh : Vivin Andhika Yuwono; Shekar Purwanti; Th.Arie Prabawati; dan Winong Rosari. Penerbit Andi: Yogyakarta.
Mathis, Robert L. \& Jackson, John H. (2004). Human Resource Manajemen. Edisi 10. Salemba Empat: Jakarta.

Mobley, W. H. (1996). Pergantian Karyawan: Sebab Akibat dan Pengendaliannya, Terjemahan. PT. Pustaka Binaman Presindo: Jakarta.

Mondy, Jery M. (2003). Compensation (First Edition). Prentice Hall Inc. Englewood: New Jersey.

Rizky, Emeraldo. (2015). Pengaruh Kompensasi Finansial Langsung Terhadap Turnover Intention Dengan Kepuasan Kerja Sebagai Variabel Mediasi (Studi Pada PG Kebon Agung Malang). 